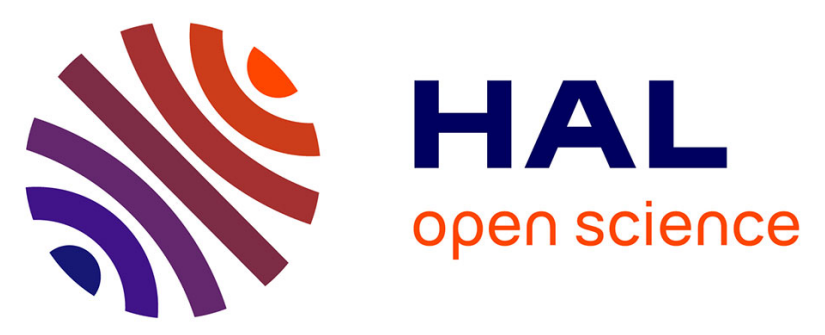

\title{
Child Income Appropriations as a Disease-Coping Mechanism: Consequences for the Health-Education Relationship
}

\author{
Renaud Bourlès, Bruno Ventelou, Maame Esi Woode
}

\section{To cite this version:}

Renaud Bourlès, Bruno Ventelou, Maame Esi Woode. Child Income Appropriations as a DiseaseCoping Mechanism: Consequences for the Health-Education Relationship. The Journal of Development Studies, 2017, 54 (1), pp.57 - 71. 10.1080/00220388.2016.1274393 . hal-01840434

\section{HAL Id: hal-01840434 \\ https://hal-amu.archives-ouvertes.fr/hal-01840434}

Submitted on 1 Apr 2019

HAL is a multi-disciplinary open access archive for the deposit and dissemination of scientific research documents, whether they are published or not. The documents may come from teaching and research institutions in France or abroad, or from public or private research centers.
L'archive ouverte pluridisciplinaire HAL, est destinée au dépôt et à la diffusion de documents scientifiques de niveau recherche, publiés ou non, émanant des établissements d'enseignement et de recherche français ou étrangers, des laboratoires publics ou privés. 


\title{
Child Income Appropriations as a Disease-Coping Mechanism: Consequences for the Health-Education Relationship
}

\author{
RENAUD BOURLÈS*, BRUNO VENTELOU**,*** \& MAAME ESI WOODE****** \\ *Ecole Centrale Marseille (Aix-Marseille School of Economics), CNRS and EHESS, Marseille, France, **Aix-Marseille \\ University (Aix-Marseille School of Economics), CNRS (Centre National de la Recherche Scientifique) and EHESS (Ecole des \\ Hautes Etudes en Sciences Sociales), Marseille, France, ***SESSTIM - INSERM (Institut National de la Santé et de la \\ Recherche médicale) UMR 912, Marseille, France
}

\begin{abstract}
This paper analyses the relationships between HIV/AIDS and education taking into account the appropriative nature of child income. Using a theoretical model, we show that considering remittances from one's child as an insurance asset can reverse the usual negative relationship between disease prevalence and educational investment. This prediction confirms the results of an empirical study conducted on data compiled from the Demographic and Health Survey (DHS) database for 12 sub-Sahara African countries for children aged between 7 and 22-years-old. Using regional HIV prevalence as a measure of health risk, we find that the 'sign of the slope' between health risk and the enrolment of children is not constant. Splitting the data based on expected remittance patterns (for example rural versus urban), we obtain that the effect is most likely driven by household characteristics related to child income appropriation.
\end{abstract}

\section{Introduction}

It is now well established that intergenerational transfers within the family play a key role in coping with risk in developing countries. For example, revenue from one's offspring can be used as security or as an insurance mechanism against shocks hurting parents. In this paper, the mechanism is used to re-investigate the relationship between health risk and education (as a way to increase the future revenue of an offspring). In particular, we analyse the extent to which this insurance role of education can explain the positive correlation observed between HIV prevalence and educational outcomes in real data for some given sub-populations, something we consider as an empirical puzzle.

This paper draws from three fields of economic literature: (i) the relationship between disease and economic development at the micro level, that is how a health shock may jeopardise a household's future capacity to save, accumulate and generate future income (Flores, O'Donnell, \& van Doorslaer, 2008; Kawabata \& Xu, 2002; Wagstaff \& van Doorslaer, 2003; Xu et al., 2003; and all the subsequent literature about 'catastrophic expenditures'), (ii) child labour and child income appropriation by parents (Basu \& Van, 1998; Schoonbroodt \& Tertilt, 2010) and in general the analysis of intergenerational remittances as an intrinsic characteristic of the developing world (Lucas \& Stark, 1985), and (iii)

Correspondence Address: Maame Esi Woode, Liverpool School of Tropical Medicine, Pembroke Place, L3 5QA Liverpool, UK. Email: maame.woode@1stmed.ac.uk 
educational choice as an insurance in the absence of social security, the most common situation in a lot of African countries (Ehrlich \& Lui, 1991).

Investment in children, both quantitatively and qualitatively, is an asset for parents, especially in developing countries. In these countries it is often seen as a substitute for social security, particularly in the old-age period of parents, which is usually characterised by the absence of labour income and elevated health risk (Ehrlich \& Lui, 1991; Michel \& Wigniolle, 2007; Nugent, 1985). Yet the fundamental nature of any insurance asset is that it is mobilised differently depending on the realisation of a risk, that is actual repayments are contingent on the occurrence of a bad event. Starting from this point (and focusing on the qualitative issue only), we add to the idea of investment in children as an insurance the notion of changing appropriation, that is the intensity with which parents invoke their 'rights' on the income of their descendants is allowed to vary depending on their health status, in a manner similar to other insurance assets.

This is not only inspired by the need to draw a parallel with the classic insurance framework, but can be connected to the notion of 'child income appropriation' (Schoonbroodt \& Tertilt, 2010). In a number of developing countries, the property rights on labour-income are shared between the different members of a household and, at least partially, submitted to discretionary re-appropriative decisions coming from the household as a community. Bazen and Salmon (2010) and McIntyre, Thiede, Dahlgren, and Whitehead (2006) showed that 'child labour' and 'premature removal from school' are connected to health shocks, suggesting that child income indeed plays the role of an insurance asset, with repayments contingent on a bad event. The recent paper of Maccini and Yang (2009) follows a similar direction, but links schooling decisions to a different type of shock (rainfall shocks) and focuses on the asymmetric effect between girls and boys in the household as in Duflo (2000). More generally, if we extend the analysis to fields outside schooling choice, numerous authors, such as Fafchamps (1992), Harrower and Hoddinott (2005) and Park (2006), consider that shocks are insured through risk sharing networks and that remittances of labour-income act as contingent repayments in case of negative shocks (Conroy, Blackie, Whiteside, Malewezi, \& Sachs, 2006; Gertler \& Gruber, 2002; Lucas \& Stark, 1985; Stark \& Lucas, 1988).

Although the idea of changing appropriation is quite general, we focus in the following on the effect of HIV prevalence on education. Indeed, on top of being the main cause of premature adult mortality, HIV-AIDS doesn't directly affect children at school-age, which eases the identification of our effect.

In the following, we first present a simple theoretical model to provide some insights into the relationship between the risk of a health shock (on adults) and schooling (of children) where education is considered as an insurance asset. We include in the modelling the property of 'changing appropriation' in case of a bad event. In the model, the health risk has the property to declare when parents are young adult and to last during the retirement period as for the HIV-AIDS case. We interpret the impact of a health shock on households' educational choice in a totally new manner which allows dealing with an empirical 'puzzle' in the HIV-AIDS domain. Indeed, our empirical strategy will point out, in accordance with the theoretical model, that an increase in the HIV-AIDS prevalence may have a positive effect on the education of children.

\section{Theoretical model}

In this section we build a stylised theoretical model to highlight the importance of child income appropriation for the relationship between education and HIV prevalence. We are more precisely interested in analysing the impact of changing appropriation (that is the fact that the part of child income appropriated by the parent can depend on the latter's health) on the effect of prevalence on the educational choices by parents. While the literature examines the quantitative choice (that is fertility) in response to health shocks (Becker \& Barro, 1988), we focus here on the qualitative decision on education enrolment, modelling a two-person household.

The aim in this first part of the paper is to highlight the effect of 'changing appropriation' on the relationship between education and health risk, in the simplest model possible. For this reason, we 
abstract away from decision on the quantity of children and from all the parental motives for education other than remittances (for example descending altruism). These other motives should not change our results, insofar as they do not change depending on the health status of the parent. As we want to focus on the educational decision in face of risk, we assume that, when taking his decision, both the parent and his child are healthy.

In the first period (activity period), the parent has a revenue, $\omega$, and chooses the proportion of time he educates his child, $t$. When not enrolled in the educational system, that is in a proportion $(1-t)$ of the same period, the child earns for the household a wage $\omega^{i}$ that can differ among children depending on a set of characteristics. The time spent in school leads to an increase in this 'basic' wage in the second period. We denote by $\rho$ the return on each unit of time spent in school, so that choosing $t$ in period 1 gives as child income $(1-t) \omega^{i}$ in period 1 , and an income of $(1+\rho t) \omega^{i}$ in period 2.

The health risk arises in the first period after a decision on the education of the child has been made. We model health risk as risk on wealth. With probability $p$, the parent falls ill for both periods. To make it more concrete, the value of $p$ will be approximated by the prevalence of HIV. For the sake of simplicity - and consistent with the pattern of HIV/AIDS - we assume that no seropositivity is declared in the second period. The parent, if ill in the first period, loses an amount $\epsilon_{1}$ of his revenue for that period and an amount $\epsilon_{2}$ of his second period revenue.

The second period is modelled, for simplicity, as a period in which the parent does not personally earn money but rather relies on the appropriation of his child's income (in accordance with the literature on old-age security). Though the presence of incomes would not affect our results, it makes it more tedious to obtain. We assume that the monetary cost of illness is higher in the first period than in the second, that is $\epsilon_{1}>\epsilon_{2}$. This is because while in the second period the loss of revenue is only due to health costs, in the first period this loss is not only due to health costs but also due to the loss of work time which translates into an income loss.

The key mechanism of our model is the assumption that the proportion of child income appropriated by the parent in the second period differs according to the parent's health status and that this proportion also differs across children. The variation may be explained, for example, by gender (Duflo, 2000; Maccini \& Yang, 2009) or location (urban/rural, de la Brière, Sadoulet, de Janvry, \& Lambert, 2002; Nugent, 1985). To be precise, we assume that the parent appropriates a proportion $\delta$ of his child's revenue if healthy and a proportion $\delta+\Delta^{i}$ if unhealthy, where $\Delta^{i}$ is not necessarily homogeneous among children; and we analyse how a positive $\Delta^{i}$ can impact the relationship between education and prevalence, that is the sign of $\frac{\partial t}{\partial p}$.

This assumption is borrowed from the literature showing that 'remittances' - generally observed among migrants - act as informal insurance. After Lucas and Stark (1985) a series of papers have related the levels of remittances with adverse shocks: Azam and Gubert (2006), Gubert (2002) or recent contributions of Halliday (2006) and Ratha (2010) (that use earthquakes as the 'bad event'). Regarding health shocks, it has been shown that remittances specifically increase in response to medical expenses of beneficiary households (Miller \& Paulson, 2007). In Cox, Eser, and Jimenez (1998), the social security motive is attested by the magnitude of the parent's age in determining remittances. Migrant remittances are in fact a special case of informal insurance systems within communities. These systems need 'reciprocity' (Fafchamps, 1992), 'punishment' (Rapoport \& Docquier, 2006), 'coerced altruism' (Alger \& Weibull, 2009) or 'stable networks' structures in communities (Bloch, Genicot, \& Ray, 2008) to insure that risk-sharing is effective (that is that the system of repayment is actually self-enforcing). For our purposes, we decide to roughly summarise these different forms of coercion by a non-negotiable appropriation rate $\delta+\Delta^{i}$ applied on child income, in which $\Delta^{i}$ represents the contingent part of the repayment (in percentage).

If we set $\beta$ as the discount factor between the two periods, the problem of the parent in period 1 becomes:

$$
\max _{t} p\left[u\left(\underline{C_{1}}\right)+\beta u\left(\underline{C_{2}}\right)\right]+(1-p)\left[u\left(\overline{C_{1}}\right)+\beta u\left(\overline{C_{2}}\right)\right]
$$


where

$$
\begin{gathered}
\overline{C_{1}}=(1-t) \omega^{i}+\omega \\
\underline{C_{1}}=(1-t) \omega^{i}+\omega-\epsilon_{1} \\
\overline{C_{2}}=\delta(1+\rho t) \omega^{i} \\
\underline{C_{2}}=\left(\delta+\Delta^{i}\right)(1+\rho t) \omega^{i}-\epsilon_{2}
\end{gathered}
$$

For the model to remain tractable and realistic, we further assume that, if healthy, the parent is always richer in the first period than in the second period, that is $\overline{C_{1}}>\overline{C_{2}} \forall t$ (that is $(1-t) \omega>\delta(1+\rho t) \omega^{i} \forall t$ or $\left.\omega>\delta(1+\rho) \omega^{i}\right)$ and always better off healthy than unhealthy, that is $\overline{C_{1}}>\underline{C_{1}}$ and $\overline{C_{2}}>\underline{C_{2}} \forall t$ (that is $\left.\Delta^{i}(1+\rho) \omega^{i}<\epsilon_{2}\right)$.

To capture the role of 'changing appropriation', we first analyse how disease prevalence impacts the educational choice in a baseline model where appropriation is the same irrespective of the health status of the parent, that is $\Delta^{i}=0$. We compare this to the case where, through appropriation, education can play an insurance role $\Delta^{i}>0$. We show that while optimal education is decreasing with disease prevalence in the baseline case, the asymmetric feature of appropriation can lead to a positive relationship.

\subsection{The benchmark case: no insurance role for education $\left(\Delta^{i}=0\right)$}

Let us first assume that appropriation of child income by the parent does not increase in case of disease, that is $\Delta^{i}=0$. In such a case, the first order condition of Equation (1) writes:

$$
-p \omega^{i} u^{\prime}\left(\underline{C_{1}}\right)+\beta p \delta \rho \omega^{i} u^{\prime}\left(\underline{C_{2}}\right)-(1-p) \omega^{i} u^{\prime}\left(\overline{C_{1}}\right)+\beta(1-p) \delta \rho \omega^{i} u^{\prime}\left(\overline{C_{2}}\right)=0
$$

That is:

$$
\frac{\mathbb{E}\left(u^{\prime}\left(C_{1}\right)\right)}{\mathbb{E}\left(u^{\prime}\left(C_{2}\right)\right)}=\beta \delta \rho
$$

To analyse the effect of disease prevalence, $p$, on the optimal time spent in school, $t$, we define

$$
f(t, p) \equiv \frac{\mathbb{E}\left(u^{\prime}\left(C_{1}\right)\right)}{\mathbb{E}\left(u^{\prime}\left(C_{2}\right)\right)}-\beta \delta \rho
$$

and use the Implicit Function Theorem:

$$
\frac{\partial t}{\partial p}=-\frac{\partial f / \partial p}{\partial f / \partial t}
$$

to obtain, 


$$
\begin{gathered}
\frac{\partial f}{\partial p}=\frac{u^{\prime}\left(\underline{C_{1}}\right) u^{\prime}\left(\overline{C_{2}}\right)-u^{\prime}\left(\overline{C_{1}}\right) u^{\prime}\left(\underline{C_{2}}\right)}{\left[\mathbb{E}\left(u^{\prime}\left(C_{2}\right)\right)\right]^{2}} \\
\frac{\partial f}{\partial t}=\frac{-\omega^{i} \mathbb{E}\left(u^{\prime \prime}\left(C_{1}\right)\right) \mathbb{E}\left(u^{\prime}\left(C_{2}\right)\right)-\delta \rho \omega^{i} \mathbb{E}\left(u^{\prime \prime}\left(C_{2}\right)\right) \mathbb{E}\left(u^{\prime}\left(C_{1}\right)\right)}{\left[\mathbb{E}\left(u^{\prime}\left(C_{2}\right)\right)\right]^{2}}>0
\end{gathered}
$$

Therefore, when $\Delta^{i}=0, \frac{\partial t}{\partial p}$ is of the sign of $\frac{u^{\prime}\left(\underline{C_{2}}\right)}{u^{\prime}\left(\overline{C_{2}}\right)}-\frac{u^{\prime}\left(\frac{C_{1}}{u^{\prime}}\right)}{\left.\overline{C_{1}}\right)}$, that is, in this benchmark case, the sign of $\frac{u^{\prime}\left(\overline{C_{2}}-\epsilon_{2}\right)}{u^{\prime}\left(\overline{C_{2}}\right)}-\frac{u^{\prime}\left(\overline{C_{1}}-\epsilon_{1}\right)}{u^{\prime}\left(\overline{C_{1}}\right)}$. As $\epsilon_{1}>\epsilon_{2}, \frac{\partial t}{\partial p}$ is then negative $\forall \overline{C_{1}}, \overline{C_{2}}$ in the case of Constant Absolute Risk Aversion (CARA) preferences $\left(u(c)=-e^{\alpha c} / \alpha\right)$ and if $\epsilon_{1} / \epsilon_{2}<\overline{C_{1}} / \overline{C_{2}}$ in the case of Constant Relative Risk Aversion (CRRA) preference $\left(u(c)=c^{1-\rho} /(1-\rho)\right)$. This can be summarised in the next proposition:

Proposition 1. If the proportion of child revenue appropriated by the parent does not increase when $i l l$, that is $\Delta^{i}=0$, the level of education, $t$, decreases with disease prevalence, $\mathrm{p}$, whatever $\overline{C_{1}}$ and $\overline{C_{2}}$ when preferences are CARA and if

$$
\frac{\epsilon_{1}}{\epsilon_{2}}<\frac{\overline{C_{1}}}{\overline{C_{2}}}
$$

\section{when preferences are CRRA}

When $\Delta^{i}=0$, the differences in income between the two states of nature (health/ill) reduce to illness cost in both period: $\overline{C_{2}}-C_{2}=\epsilon_{2}$ for any $t$ (and $\overline{C_{1}}-C_{1}=\epsilon_{1}$ for any $t$ ). In that sense, the income risk faced by the parent is independent of the level of education he chooses for his child. Therefore, the educational choice reduces to a wealth transfer between the two periods. In this benchmark case education then plays the same role that savings would play. Therefore, in a richer version including savings, only one instrument would be used at the optimum, when appropriation has no insurance role $\left(\Delta^{i}=0\right)$. As $\epsilon_{1}>\epsilon_{2}$, for a given risk preference, an increase in risk would then lead to a wealth transfer from the second to the first period (that is a decrease in education). In the general case, this effect however interacts with an income effect through the change in (absolute) risk aversion due to change in wealth. Constant Absolute Risk Aversion (CARA) preferences abstract from this second order effect. In the case of CRRA preferences, we need in addition that the ratio of the income losses due to illness between the two periods be lower than the ratio of incomes between the two periods when healthy, which seems to be in line with the definition of the second period as a retirement period.

Therefore, our benchmark case result is a direct consequence of the intertemporal smoothing decisions obtained in this framework. A health shock implies, first of all, household impoverishment, with income losses of $\epsilon_{1}$ and $\epsilon_{2}$. For $\epsilon_{1}>\epsilon_{2}$, we have that the education decision is downsized, to compensate potential income-loss in period 1. The slope between health risk, $p$, and the level of education, $t$, is then negative as in Fortson (2011), who uses a different micro modelling technique (human capital decision and mortality risk).

\subsection{Assuming an insurance role for education $\left(\Delta^{i}>0\right)$}

We now assume that the part of child revenue appropriated in period 2 by the parent is higher in case of ill health, that is $\Delta^{i}>0$. 
When $\Delta^{i}>0$, the effect of illness is no longer independent of $t$ in the second period. Indeed, we have $\overline{C_{2}}-\underline{C_{2}}=\epsilon_{2}-\Delta^{i}(1+\rho t) \omega^{i}$. Moreover, education then corresponds to a transfer, not only between periods, but also between states. In that sense, education has an insurance motive. This is likely to modify how investment in education responds to health shocks. At least two effects are at stake: (i) $\Delta^{i}$ increases the expected return on education (all the more as $p$ increases), (ii) $\Delta^{i}$ decreases the size of the risk in the second period (all the more as $t$ increases). The aim of the current section is to analyse the effect of these two mechanisms on the relationship between education and health risk.

When $\Delta^{i}>0$, the first order condition of Equation (1) becomes:

$$
g(t, p) \equiv \frac{\mathbb{E}\left(u^{\prime}\left(C_{1}\right)\right)-p \beta \Delta^{i} \rho u^{\prime}\left(\underline{C_{2}}\right)}{\mathbb{E}\left(u^{\prime}\left(C_{2}\right)\right)}-\beta \delta \rho=0
$$

with,

$$
\frac{\partial g}{\partial p}=\frac{u^{\prime}\left(\underline{C_{1}}\right) u^{\prime}\left(\overline{C_{2}}\right)-u^{\prime}\left(\overline{C_{1}}\right) u^{\prime}\left(\underline{C_{2}}\right)-\beta \Delta^{i} \rho u^{\prime}\left(\underline{C_{2}}\right) u^{\prime}\left(\overline{C_{2}}\right)}{\left[\mathbb{E}\left(u^{\prime}\left(C_{2}\right)\right)\right]^{2}}
$$

Note here that two forces are at play when we compare Equation (5) to Equation (2): (i) an extra negative term appears in the numerator of Equation (5) and (ii) $\Delta^{i}$ (positive) increases $C_{2}$ so that we now have $C_{2}>\overline{C_{2}}-\epsilon_{2}$. On the one hand, education has a higher return for the parent due to their ability to appropriate more, but on the other hand, the extra (expected) wealth in the second period reduces the need for education for intertemporal consumption smoothing. Therefore, the sign of $\frac{\partial g}{\partial p}$ highly depends on the time preferences of the parent (that is $\beta$ ). More precisely, $\frac{\partial g}{\partial p}$ is positive if and only if $\beta$ is low enough:

$$
\beta<\frac{1}{\Delta^{i} \rho}\left[\frac{u^{\prime}\left(\underline{C_{1}}\right)}{u^{\prime}\left(\underline{C_{2}}\right)}-\frac{u^{\prime}\left(\overline{C_{1}}\right)}{u^{\prime}\left(\overline{C_{2}}\right)}\right] \equiv \bar{\beta}
$$

with $\bar{\beta}>0$ positive when $u^{\prime}\left(\underline{C_{1}}\right) u^{\prime}\left(\overline{C_{2}}\right)>u^{\prime}\left(\overline{C_{1}}\right) u^{\prime}\left(\underline{C_{2}}\right)$, that is under the same condition (although evaluated at another equilibrium) than the one needed for $\frac{\partial t}{\partial p}<0$ when $\Delta^{i}=0$. Moreover

$$
\begin{aligned}
\frac{\partial g}{\partial t}= & \frac{-\omega^{i} \mathbb{E}\left(u^{\prime \prime}\left(C_{1}\right)\right) \mathbb{E}\left(u^{\prime}\left(C_{2}\right)\right)-\delta \rho \omega^{i} \mathbb{E}\left(u^{\prime \prime}\left(C_{2}\right)\right) \mathbb{E}\left(u^{\prime}\left(C_{1}\right)\right)}{\left[\mathbb{E}\left(u^{\prime}\left(C_{2}\right)\right)\right]^{2}} \\
& -\frac{p \Delta^{i} \rho \omega}{\left[\mathbb{E}\left(u^{\prime}\left(C_{2}\right)\right)\right]^{2}}\left\{u^{\prime \prime}\left(\underline{C_{2}}\right) \mathbb{E}\left(u^{\prime}\left(C_{1}\right)\right)+(1-p) \beta \rho \Delta^{i} u^{\prime \prime}\left(\underline{C_{2}}\right) u^{\prime}\left(\overline{C_{2}}\right)\right. \\
& \left.+(1-p) \beta \rho \delta\left[u^{\prime \prime}\left(\underline{C_{2}}\right) u^{\prime}\left(\overline{C_{2}}\right)-u^{\prime \prime}\left(\overline{C_{2}}\right) u^{\prime}\left(\underline{C_{2}}\right)\right]\right\}
\end{aligned}
$$

As stated in the previous section, the first term of Equation (6) is positive for all increasing and concave utility functions. In these cases, the first two terms of the brace are negative. However, the sign of the last term of the brace depends on the shape of risk aversion with respect to income. It is nil in the case of CARA and negative if the absolute risk aversion $\left(-\frac{u^{\prime \prime}(C)}{u^{\prime}(C)}\right)$ is decreasing, as in the CRRA case. Therefore $\frac{\partial g}{\partial t}$ is positive in the case of CARA or CRRA preferences. Indeed, the way risk aversion evolves with wealth determines to what extent the parent wants to reduce income fluctuation in the second period (when relatively poorer), by investing in child education.

Proposition 2. If the proportion of child revenue appropriated by the parent is higher in the case of ill health $\left(\Delta^{i}>0\right)$, the level of education decreases with disease prevalence if and only if agents are impatient enough $(\beta<\bar{\beta})$, when preferences are CARA or CRRA. 
In the other case, that is if $\beta>\bar{\beta}$, the level of education increases in $p$ (with $\bar{\beta}>0$ whenever $\epsilon_{1}>\epsilon_{2}$ in the CARA case, and $\bar{\beta}>0$ if and only if $\frac{\epsilon_{1}}{\epsilon_{2}}<\frac{\overline{C_{1}}}{\overline{C_{2}}}$ - that is under condition (4) - when utility is CRRA).

Remark 1. The role of changing appropriation (that is the 'insurance role' of education) can be inferred from this condition. When $\Delta^{i}$ is positive, the negative slope between prevalence and education (found when $\Delta^{i}=0$, see Proposition 1) has a lesser validity set. For a high level of $\beta$ (that is $\beta>\bar{\beta}$ ), we even find that the sign changes, with the slope becoming positive. In that sense, the existence of extra-appropriation contingent to illness can lead to a positive relationship between education and health risk.

The intuition behind this result is quite simple. Assuming a change in the degree of appropriateness under bad health gives education an insurance role, calling for an increase in education when risk increases. The total effect of an increase in disease prevalence depends on whether this 'insurance effect' dominates the consumption smoothing effect found in the previous section. According to Proposition 2, the insurance effect dominates when the discount factor is large enough, that is, when the weight of the second period (the one in which education plays its insurance role) is large enough in the intertemporal utility function. Therefore, if both savings and education were included in a richer modelling, they would be effectively used at the optimum, with the result that saving would play the role of intertemporal consumption smoothing, and education would only be used for its insurance motive. It should be noted that Proposition 1 and 2 (and therefore Remark 1) holds whatever $\overline{C_{1}}$ and $\overline{C_{2}}$ for CRRA utility functions in the case of health shocks proportional to wealth.

Remark 2. Note that the proposition 2 correlates $p$, at a given period, with $t$, at the same period, suggesting that the empirical test can simply consist in testing the relationship in the contemporaneous observations of $t$ (education) and $p$ (prevalence).

\subsection{Identification strategy: the HIV/AIDS and school enrolment relationship}

The theoretical results (Proposition 1 and Proposition 2) provide us with explanations for any positive correlation that could be observed between regional HIV prevalence and school enrolment in SubSaharan Africa (SSA). The model shows that, if parents expect to be able to receive help from their children, they would be more likely to invest in the education of their descendants when the HIV-risk increases, at least under certain circumstances (depending on $\Delta^{i}$ ).

Empirical investigations support these mechanisms if we find that (i) the relationship between health risk and education is generally negative when parents expect not to be able to appropriate more from their children when in ill health, but (ii) can become positive when education plays an important insurance role, for example for sub-groups that are presumed to present the characteristic of highly appropriable children's income. In the next sections, we investigate these implications on microdata assuming that child or parent/household characteristics lead to different values of extra-appropriations opportunities, $\Delta^{i}$, that is, to heterogeneity in the insurance role of education. We will successively deal with two major characteristics shaping the value of $\Delta^{i}$ : rural versus urban areas (with the implicit assumption that rural areas are more favourable to an insurance role for education returns [de la Brière et al., 2002; Nugent, 1985]), and the age-group of the child (as a proxy for the education level investment we consider: primary/secondary/universities).

Identification will lie in the following method: the two characteristics, separated and crossed, will be used as a stratification device for the econometric estimations, and the respective signs (and significance) of the HIV/education slopes obtained for each sub-group will be judged as a decisive support of the insurance role of education. 


\section{Materials and methods}

\subsection{Data overview}

We use the nationally representative cross-sectional data set, the Demographic and Health Survey (DHS), for 12 SSA countries (Burkina Faso [2010; 2003], Cameroon [2011; 2004], Congo Kinshasa [2013; 2007], Ethiopia [2011; 2005], Ghana [2014; 2003], Guinea [2012; 2005], Kenya [2008; 2003], Lesotho [2009; 2004], Liberia [2013; 2007], Malawi [2010; 2004], Sierra Leone [2013; 2008], and Zimbabwe [2010/11; 2005]) to analyse the effect of HIV risk, proxied by local HIV prevalence, on education. The DHS is collected periodically at both the individual and household level. It contains household data on basic characteristics of members of each household and also specific data on both male and female household members between the ages 15 and 49 inclusive. We focus on the 12 subSaharan countries for which HIV testing was carried out in at least a previous wave of the survey, as the information on the lagged HIV prevalence has been necessary for dealing with the endogeneity issue. We focus on individuals between the ages of 7 and 22 inclusive. This large age range allows us to take into account the impact at different educational levels, namely, primary, secondary and tertiary.

3.1.1. Education. The educational system in SSA is quite diverse. It is in general structured around four levels, namely, primary, secondary, technical or vocational, and university with basic tertiary education ending at the age of 22, see Table S1 in the Supplementary Material. Enrolment (attendance) is the usual indicator of education in studies on child labour and schooling (Fortson, 2011). We use this variable as our dependent variable. The regional average rate of enrolment in the 12 countries ranges from 16.5 per cent in Burkina Faso to 37.0 per cent in Kenya (see Table S2 in the Supplementary Material for further statistics).

3.1.2. Community prevalence. As part of the DHS survey, a voluntary AIDS test was carried out by means of dried blood spot samples collected on special filter paper through blood from a finger prick. Participants were initially selected at random and asked whether they consented to having an HIV test. For confidentiality purposes the results were linked to households after household and community identifiers were scrambled (Mishra et al., 2007). The communities are non-overlapping districts within the 12 countries and we select in total 108,351 children in 10,442 households in 105 regions.

In order to calculate the regional HIV prevalence, we use the results obtained from the test and reported as part of the survey results. Community prevalence is calculated as the proportion of individuals within the ages of 15-49 in the community who were HIV+ based on tests carried out during the survey, weighted at the community level.

The lower panel of Table S2 in the Supplementary Material gives a summary of the HIV prevalence in the different countries. We focus only on households in which no member has HIV+ status and no member for which HIV status is unknown.

A quick glance at the correlation between regional enrolment rates and regional HIV prevalence rates reveal different relationships. From Figure 1 we see a variance in correlation depending on the region of residence. While HIV originated in central Africa, it has spread to other parts of Africa with varying speed and varying prevalence rates. These variances could generally be due to differences in culture and norms as well as policies. This also means that the relationship between HIV and any other variable could possibly be different depending on the location of the country of residence.

One possible explanation suggested by our theoretical model for the observed heterogeneity in correlations could be explained by differences in appropriation of child income. For this purpose, we split the data based on the age of the child and on the location of the child's residence. This is illustrated in Figure S1 in the Supplementary Material. Remittances from children to parents are shown to vary based on location of residence, with remittances expected to be lower among urban households as compared to rural households (Nugent, 1985). We find, again, varying relationships. For rural areas, the effect remains mainly positive or insignificant. Finally, when we focus on university aged individuals (UAIs) we seem to find a generally negative or insignificant correlation in all regions 

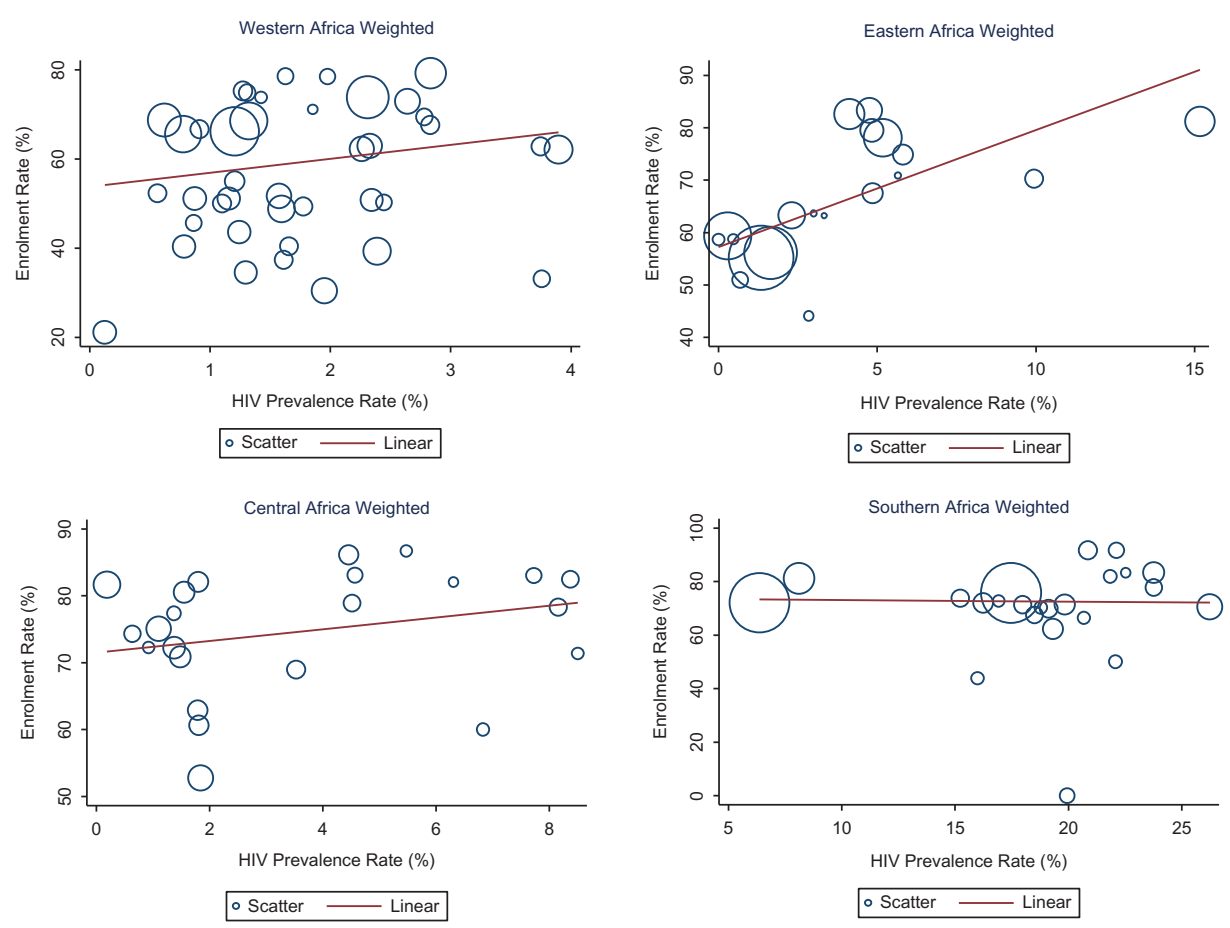

Figure 1. Regional enrolment per sub-Saharan Africa region.

except in urban East Africa and in Central Africa where the correlation appears positive (see Figure S1 Panel C in the Supplementary Material). We explore this later in the empirical model.

\subsection{Econometric model}

Given the different start date of the epidemic, the differences in cultural norms and varying trends across the four sub-Saharan Africa (SSA) regions, we group the countries based on these geographical regions. The individuals are nested within households which are in turn nested within regions and countries. We therefore cluster at the household level, controlling for region and country of residence. The clustered probit model allows us to take into account random components at the individual, household, country-specific region and country level. Ignoring the clustering would imply that the independence condition would be violated and the standard errors underestimated (Guo \& Zhao, 2000). We estimate the following equation:

$$
y_{i}=\alpha_{0}+\alpha X_{i}+\beta Z_{j}+\mu V_{c}+\gamma W_{k}+\eta H I V+\theta_{i}
$$

where $i$ represents the individual, $j$ the household, and $k$ the region. In addition to HIV prevalence rates $(H I V)$, we control for child $\left(X_{i}\right)$, household $\left(Z_{j}\right)$, community $\left(V_{c}\right)$ and other regional level $\left(W_{k}\right)$ characteristics including, age, gender and residency status of the child as well as the child's relation to the household head, the proportion of household members below five years of age, the type of place of residence, the household's income category, and the gender, age and educational level of the household head.

Regarding these main characteristics (see Table S3 and Table S4 in the Supplementary Material for detailed definitions of the variables used and their descriptive statistics), our sample contains children of average age 13.3 years old with slightly more females than males. A third of the households the 
children live in are located in rural areas with 72.5 per cent of them headed by males. About 32.0 per cent of the household heads are educated.

To fit with the insurance-demand behaviour summarised in Proposition 2, we first run a model in which the HIV prevalence is measured by the community (cluster) level prevalence of the current DHS wave $\left(H I V_{c}^{T}\right)$. However, recognising that when the parent makes a decision on the schooling of children, the only health risk information available to them are based on earlier data, we alternatively measure HIV prevalence using the regional level prevalence from the previous DHS wave $\left(H I V_{k}^{T-1}\right)$. The DHS not following the same respondents nor villages, the waves do not involve the same clusters, forcing us to go to the regional level.

3.2.1. Non-response: community HIV prevalence. As we are calculating the prevalence rate from sample data, there is the risk of errors in measurement. Not all individuals between the ages of 15 and 49 inclusive, were sampled and tested for HIV. Of those sampled, not all agreed to be tested for HIV. Non-response could bias our estimates and it is important to check for this. Then, we collected the standard-errors for our prevalence data and use monte-carlo simulations to estimate the average regional prevalence after $1,000,000$ simulations. We verify that this correction is not driving our results. We find that the results do not change significantly even after controlling for possible nonresponse bias. We therefore proceed with our original model. The results are available on request.

3.2.2. Endogeneity. The statistical statement that 'prevalence affects enrolment' must be confronted with the issue of endogeneity. Among other reasons, the apparent correlations between the two interest-variables could come from an omitted variable. Nevertheless, due to the structure of our model, a classical IV-regression method would also lead to biased results. The IV technique is unable to take into account the multilevel nature of our data collection, especially given that our (possibly) endogenous variable - prevalence - is not defined at the same level as our main dependent variable education. To correct for the potential bias, we implement a 'control function approach' that Wooldridge suggests to apply in this case (Wooldridge, 2015). The control function approach is an adaptation of the IV technique to nonlinear models. It is commonly used in health economics and health services research under the denomination of a 'two-stage residual inclusion' (2SRI) model (Terza, Basu, \& Rathouz, 2008).

We first select instruments that should affect prevalence and not school enrolment. The first instrument is the regional average number of sexual partners per person and the second, the regional condom use rate; both taken from the previous DHS waves. In cases where HIV prevalence from the current wave is our main explanatory variable, we also instrument for prevalence from the previous wave (both are then aggregated at the regional level). At the first stage, we use the instruments to predict the prevalence rates at the country regional level using a fractional probit regression of the form:

$$
\hat{\mathrm{p}}_{\mathrm{k}}=\phi\left(\tau_{k}^{\prime} \hat{X}_{k}\right)
$$

where, in addition to the instruments already discussed, the matrix $\hat{X}_{k}$ includes community aggregate values of covariates used at the second stage. We then estimate the generalised residuals $r_{k}$ of Equation (8): $r_{k}=p_{k}-\hat{\mathrm{p}}_{k}$. We run separate regressions for urban and rural areas. The results of this first-stage regression for SSA are available in the Supplementary Materials (Table S6). From this table we note that while the lagged prevalence has a positive effect on HIV prevalence for the current wave, it is only significant in rural areas. When we use the previous wave HIV prevalence, we find that both the number of sexual partners and the use of condoms significantly affect HIV prevalence, irrespective of place of residence. The regional results are available on request.

At the second stage we use the predicted prevalence rates as our covariate of interest, see Table S7a and S7b in the Supplementary Material for results pertaining to SSA. The regional results are available on request. The second-stage regression is a multilevel model as in the original equation: 


$$
y_{i}=\alpha_{0}+\alpha X_{i}+\beta Z_{j}+\gamma W_{k}+\eta H I V_{k}+\vartheta r_{k}+\theta_{i}(9)
$$

where the inclusion of $r_{k}$ ensures that the estimation of the slope, $\eta$, significantly different from 0 is not artificial (not only generated by hidden correlations between error-terms in the data generating process of the two variables of interest). To test for endogeneity of regional HIV prevalence, we use the heteroscedasticity-robust $t$ statistic on $r_{k}$ (Wooldridge 2015). Our regressions are run in STATA 14.

\section{Results}

The results of the initial model are presented in Table 1. A simple probit model is first estimated for Equation (9). This group of results generally shows an insignificant relationship between community HIV prevalence and household's decision to enrol their children in school in rural areas and a positive relationship for children in urban areas for children of middle school age (14-17 year olds).

As previously discussed, one of the main drawbacks of this model comes from the fact that, when parents are making decisions concerning the schooling of their children, the only information on HIV prevalence available to them is that from previous years. To account for this, we rerun the models using prevalence registered from the previous waves of DHS, as our variable of interest. Results of this second probit model are also reported in Table 1.

Interestingly the only significant effect we find when we use prevalence data from the current wave is for urban middle school aged children, where it is positive. When we switch to prevalence data from the previous waves, we find a positive effect for primary school aged children (7-13) in both urban and rural areas, the effect is negative and significant for middle school children in rural areas and remains insignificant for university aged children. This second probit model seems to provide better significance in the estimates and to confirm the idea of signs of slopes depending on age and areas.

To deal with the (possible) endogeneity issue, we decided to run the 'control function' model, added to the use of prevalence at period T-1 which seems to be informationally more relevant. The results are presented in columns 3-5 of Table 2, for SSA as a whole and for the four sub-regions of Africa. Results with prevalence measured at period T-1 are presented in columns 6-8 of Table 2.

Taking SSA as a whole, we re-observe 'inconsistencies' in slopes: across regions in SSA for the different age groups between rural residents and urban residents. On the whole (SSA) sample, the control function approach confirms a positive effect for the youngest children that becomes negative for older ones. These effect are significant for young children and old children when using prevalence from the previous waves.

We use interaction effects to compare the coefficients across the different groups in each region to check whether the results obtained from urban areas are indeed different from those of rural areas. The

Table 1. Impact of community HIV prevalence on schooling

\begin{tabular}{cccccc}
\hline & \multicolumn{2}{c}{ Probit model; prevalence latest wave } & & \multicolumn{2}{c}{ Probit model; prevalence previous wave } \\
\cline { 2 - 3 } \cline { 6 - 6 } & Urban & Rural & & Urban & Rural \\
\hline $\mathbf{7 - 1 3}$ & 0.009 & 0.005 & & $\mathbf{0 . 0 5 3 * * *}$ & $\mathbf{0 . 0 1 0 *}$ \\
& $(0.005)$ & $(0.003)$ & & $(\mathbf{0 . 0 1 0 )}$ & $\mathbf{( 0 . 0 0 5 )}$ \\
$\mathbf{1 4 - 1 7}$ & $\mathbf{0 . 0 2 2 * * *}$ & -0.006 & & $\mathbf{0 . 0 4 9 * * *}$ & $\mathbf{- 0 . 0 3 4 * * *}$ \\
& $\mathbf{( 0 . 0 0 3 )}$ & $(0.004)$ & & $\mathbf{( 0 . 0 0 5 )}$ & $\mathbf{( 0 . 0 0 5 )}$ \\
$\mathbf{1 8 - 2 2}$ & -0.003 & 0.001 & & -0.015 & -0.009 \\
& $(0.005)$ & $(0.003)$ & & $(0.011)$ & $(0.005)$ \\
\hline
\end{tabular}

Notes: $* * * p<0.001, * * p<0.05, * p<0.1$. The numbers in brackets are robust standard errors. The full regression results (including controls) can be found in the Supplementary Materials (Table S5a and S5b). The bold figures indicate coefficients with a p-value inferior to $10 \%$. 
Table 2. Impact of regional HIV prevalence on enrolment

\begin{tabular}{|c|c|c|c|c|c|c|c|}
\hline & & \multicolumn{3}{|c|}{ Control function (latest wave) } & \multicolumn{3}{|c|}{ Control Function (previous wave) } \\
\hline & & $7-13$ & $14-17$ & $18-20$ & $7-13$ & $14-17$ & $18-20$ \\
\hline \multirow[t]{3}{*}{ SSA } & Urban & $\begin{array}{l}0.116 * * * \\
(0.023)\end{array}$ & $\begin{array}{c}0.043 * \\
(0.018)\end{array}$ & $\begin{array}{c}0.032 * \\
(0.014)\end{array}$ & $\begin{array}{l}0.090 * * * \\
(0.014)\end{array}$ & $\begin{array}{l}-0.018 \\
(0.013)\end{array}$ & $\begin{array}{l}-0.054 * * * \\
(0.011)\end{array}$ \\
\hline & Rural & $0.086 * * *$ & $0.029 * * *$ & 0.005 & $0.106 * * *$ & 0.011 & $-0.021 *$ \\
\hline & & $(0.007)$ & $(0.006)$ & $(0.006)$ & $(0.008)$ & $(0.008)$ & $(0.008)$ \\
\hline \multirow[t]{4}{*}{ Central Africa } & Urban & $\mathbf{0 . 1 8 4} * * *$ & 0.095* & $0.064 * *$ & $0.172 * * *$ & $\mathbf{0 . 0 5 9} * *$ & $0.043 * *$ \\
\hline & & (0.042) & $(0.037)$ & $(\mathbf{0 . 0 2 4})$ & (0.021) & (0.018) & (0.015) \\
\hline & Rural & $0.115 * * *$ & 0.024 & 0.009 & $0.157 * * *$ & $0.057 * *$ & 0.022 \\
\hline & & $(0.017)$ & $(0.021)$ & $(0.018)$ & $(0.016)$ & $(0.017)$ & $(0.016)$ \\
\hline \multirow[t]{4}{*}{ Eastern Africa } & Urban & 0.049 & $-0.102 *$ & $-0.113 * *$ & $0.116^{*}$ & $-0.072 *$ & $-0.139 * * *$ \\
\hline & & $(0.058)$ & $(0.052)$ & (0.042) & (0.049) & (0.029) & (0.024) \\
\hline & Rural & $0.396 * * *$ & $0.070 *$ & 0.001 & $0.290 * * *$ & $0.155 * * *$ & $0.047 * * *$ \\
\hline & & (0.046) & $(0.031)$ & $(0.013)$ & (0.020) & $(0.018)$ & $(0.013)$ \\
\hline \multirow[t]{4}{*}{ Southern Africa } & Urban & 0.001 & 0.026 & $0.091 * * *$ & 0.006 & -0.010 & $-0.077 * * *$ \\
\hline & & $(0.032)$ & $(0.024)$ & $(0.018)$ & $(0.018)$ & $(0.020)$ & (0.018) \\
\hline & Rural & $0.019 *$ & 0.002 & -0.010 & 0.013 & -0.010 & $-0.021 * *$ \\
\hline & & $(0.008)$ & $(0.008)$ & $(0.009)$ & $(0.007)$ & $(0.006)$ & (0.007) \\
\hline \multirow[t]{4}{*}{ Western Africa } & Urban & -0.016 & 0.076 & 0.070 & 0.004 & $-0.119 * *$ & $-0.120 * *$ \\
\hline & & $(0.036)$ & $(0.048)$ & $(0.036)$ & $(0.033)$ & $(0.041)$ & $(\mathbf{0 . 0 3 7})$ \\
\hline & Rural & $0.429 * * *$ & $0.355^{* * *}$ & 0.010 & $0.101 * *$ & $-0.104 *$ & $-0.258 * * *$ \\
\hline & & (0.039) & $(0.049)$ & $(0.046)$ & $(\mathbf{0 . 0 3 5 )}$ & $(0.044)$ & (0.051) \\
\hline
\end{tabular}

Notes: ${ }^{* * *} \mathrm{p}<0.001,{ }^{* *} \mathrm{p}<0.05,{ }^{*} \mathrm{p}<0.1$. The numbers in brackets are robust standard errors. The full regression results for SSA (including controls) can be found in the Supplementary Materials (Table S7a and S7b) and the rest on request. The bold figures indicate coefficients with a p-value inferior to $10 \%$.

results are reported in Tables S5a and S5b in the Supplementary Material. We find that there are generally significant differences across age and location.

We then split our sample, depending on African regions. This confirms our results. Positive coefficients for young (7-13) children in rural areas appears highly significant in areas where the HIV epidemic is worst (Central and Eastern Africa). Similarly, the negative effect of prevalence on school enrolment for the oldest children turn out significant in some of the areas.

Our test of instrument strength indicates that both the number of sexual partners and the rate of use of condoms are strong instruments for HIV prevalence. These results are presented in Table S8 of the Supplementary Material. Endogeneity/exogeneity tests indicate that regional HIV prevalence is generally endogenous (in urban West Africa and rural East Africa). These results are presented in Table S9 of the Supplementary Material.

Our results seem to indicate that Western Africa has a particular feature. An increase in HIV prevalence leads households to reduce their educational investments in older children, having in mind that we consider families not affected by the disease. This sub-region of Africa has, however, the lowest levels of HIV prevalence. In regions where the disease has already had a devastating effect (or where the disease is still raging), the increase in health risks seems to lead to an increase in educational investments especially in rural areas.

The insurance role for education appears to be very strong for primary education investment. In late secondary school to university, any educational investments might prove futile for the parent as appropriation is more difficult (child individualism). They would also most likely be dead by the time the child starts working and gets returns form schooling investment. These results obtained on sub-samples were at the origin of what we called earlier the 'empirical puzzle', which stimulate our effort to build a theoretical model dealing with a changing appropriation. For the subgroup of children who are highly appropriable, the insurance role of education can lead to a positive and significant relationship between the probability of becoming HIV+ and educational investment. 


\section{Conclusion}

We have analysed the impact of health risk, and specifically HIV/AIDS risk, on education, taking into account the fact that education of children can act as a form of insurance against shocks, and in this particular case, health shocks in old-age. We first built a theoretical model where active adults invest in the education of their children. We find that in the absence of extra appropriation in the case of ill health, an increase in the probability of falling ill leads to a reduction in the time children spend in school. However, when there is an opportunity for extra appropriation in bad health events, we have that health risk may in some cases lead to an increase in the amount of education, especially when a family's response in terms of required remittance (the extra amount appropriable) is very high.

We test the idea that an increase in the probability of falling ill can lead to an increase in educational investments and find that (i) for children in urban areas the effect is either negative and significant or generally insignificant in SSA regions that currently or previously had high disease prevalence but that (ii) we find a positive and significant effect in the rural areas of these regions. For Western Africa where the disease prevalence has generally been low, we find a negative effect across the two areas of residence. Controlling for possible endogeneity, we find a negative effect of community HIV prevalence on enrolment, but still a positive effect among rural children in all regions but West Africa.

We therefore verify the conventional result of a negative relationship between education and HIV prevalence, as in Fortson (2011), for a sub-sample of children: children living in West Africa. But we enrich it for children of another type: children in rural areas in the other SSA regions for whom the relationship seems to be positive (a result already emphasised by some [Bennell, 2004; Bennell, Hyde, \& Swainson, 2002]).

This empirical 'puzzle', that is this surprising non-monotonicity, opens the door to a new theoretical reasoning different from the usual one explaining how households cope with health shocks. Our interpretation of these results is that, depending on how appropriable the income of one's child is, education acts as an insurance asset, providing protection in bad events. This attribute could reverse the sign of the relationship between disease prevalence and schooling, as exhibited by the different subgroup estimates. Our theoretical model provides one possible explanation of such a mechanism.

These results suggest that the role of remittance systems on educational investment decisions would be an interesting avenue to explore. In our empirical setting, we have proxied differences in appropriateness by exogenous characteristics (urban/rural areas) that have been proven in other papers to be related to appropriateness. However, more attention needs to be paid to our key mechanism of 'changing appropriateness', for example by analysing to what extent (and based on which characteristics) remittances change depending on the health status of parents at old-age. To fully test for the existence of an insurance nature of education (through changing appropriation, in relation to parental health) more data would be needed. Full identification would require panel data on remittances, on health risk before infection, and initial health status.

Last, regarding the policy implications of our work, it seems worth emphasising that the general picture we obtain is that HIV/AIDS indeed has a negative impact on school enrolment for male children in urban households. When we obtain a positive effect of HIV risk rate (community prevalence), we must keep in mind that the estimated coefficient evaluates the actual consolidation of different forces, sometimes positive (insurance effect) and generally negative (income effect, supply side effect on the educational sector). This is clearly demonstrated by the various stratifications of the estimations, showing that the positive effect only dominates for children in rural areas. In brief, the findings of this paper clearly do not support a decrease in schooling assistance in least developed countries. To the contrary, the lesson is that supply-oriented policies should be favoured, as the demand for education can be partly self-sustained, given the insurance effect.

\section{Acknowledgements}

The authors would like to thank participants of the GREQAM Doctoral seminars and the DEFI Economic Development Seminars. A special thank you goes to Pr. Cecilia Garcia-Peñalosa, Pr. 
Pierre Phillipe Combes, and Pr. Alice Fabre. The views expressed in this paper are those of the authors alone and do not necessarily represent the views or policies of any of the affiliated institutes where the research was carried out. We are also grateful to the discussants and participants of the $16^{\text {th }}$ Theories and Methods in Economics conference in Nantes, France, The ECHE 2012 Conference held in Zurich, Switzerland and the $27^{\text {th }}$ EEA 2012 Conference held in Malaga, Spain as well as the $17^{\text {th }}$ SYME 2012 workshop held in Mannheim, Germany for helpful discussion and comments.

\section{Funding}

This work has been completed thanks to the support of the A*MIDEX project SANTEMED (n ANR11-IDEX-0001-02) funded by the «Investissements d'Avenir» French Government program, managed by the French National Research Agency (ANR)».

\section{Disclosure statement}

No potential conflict of interest was reported by the authors.

\section{References}

Alger, I., \& Weibull, J. W. (2009). Family ties, incentives and development: A model of coerced altruism. In K. Basu \& R. Kanbur (Eds.), Arguments for a better world: Essays in honor of Amartya Sen (Vol. II, pp. 178-201). Oxford: Oxford University Press.

Azam, J.-P., \& Gubert, F. (2006). Migrants' remittances and the household in Africa: a review of evidence. Journal of African Economies (AERC Supplement), 15, 426-462. doi:10.1093/jae/ej1030

Basu, K., \& Van, P. H. (1998). The economics of child labour. The American Economic Review, 88, $412-427$.

Bazen, S., \& Salmon, C. (2010). The impact of parental health o child labour. Economic Bulletin, 30, $2549-2557$.

Becker, G. S., \& Barro, R. J. (1988). A reformulation of the economic theory of fertility. The Quarterly Journal of Economics, 103, 1-25. doi: $10.2307 / 1882640$

Bennell, P. (2004). Aids in Africa: Three scenarios for the education sector (Report Prepared for the UNAIDS project, AIDS in Africa: scenarios for the future). Geneva: UAIDS.

Bennell, P., Hyde, K., \& Swainson, N. (2002). The impact of the HIV/AIDS epidemic on the education sector in sub-sahara Africa. Brighton: Centre for International Education: University of Sussex Institute of Education.

Bloch, F., Genicot, G., \& Ray, D. (2008). Informal insurance in social networks. Journal of Economic Theory, 143, 36-58. doi:10.1016/j.jet.2008.01.008

Conroy, A., Blackie, M., Whiteside, A., Malewezi, J., \& Sachs, J., (2006). Poverty, AIDS and hunger: Breaking the poverty trap in Malawi (1st ed.) New York: Palgrave MacMillan.

Cox, D., Eser, Z., \& Jimenez, E. (1998). Motives for private transfers over the life cycle: An analytical framework and evidence for Peru. Journal of Development Economics, 55, 57-80. doi:10.1016/S0304-3878(97)00056-4

de la Brière, B., Sadoulet, E., de Janvry, A., \& Lambert, S. (2002). The roles of destination, gender and household composition in explaining remittances: An analysis for the Dominican Sierra. Journal of Development Economics, 68, $309-328$. doi:10.1016/S0304-3878(02)00015-9

Duflo, E. (2000). Child health and household resources in South Africa: Evidence from the old age pension program. The American Economic Review, 90, 393-398. doi:10.1257/aer.90.2.393

Ehrlich, I., \& Lui, F. T. (1991). Intergenerational trade, longevity and economic growth. Journal of Political Economy, 99 , 10291059. doi: $10.1086 / 261788$

Fafchamps, M. (1992). Solidarity networks in preindustrial societies: Rational peasants with a moral economy. Economic Development and Cultural Change, 41, 147-174. doi:10.1086/452001

Flores, G. K. J., O’Donnell, O., \& van Doorslaer, E. (2008). Coping with healthcare costs: Implications for the measurement of catastrophic expenditures and poverty. Health Economics, 17, 1393-1412. doi:10.1002/hec.1338

Fortson, J. (2011). Mortality risk and human capital investment: Theimpact of HIV/AIDS in sub-saharan Africa. Review of Economics and Statistics, 93, 1-15. doi:10.1162/REST_a_00067

Gertler, P., \& Gruber, J. (2002). Insuring consumption and against illness. The American Economic Review, 92, 51-70. doi: $10.1257 / 000282802760015603$

Gubert, F. (2002). Do migrants insurethose who stay behind? Evidence from the Kayes area (western Mali). Oxford Development Studies, 30, 267-287. doi:10.1080/1360081022000012699

Guo, G., \& Zhao, H. (2000). Multilevel modeling for binary data. Annual Review of Sociology, 26, 441-462. doi:10.1146/ annurev.soc.26.1.441 
Halliday, T. (2006). Migration, risk and liquidity contraints i El Salvador. Economic Development and Cultural Change, 54, 893-925. doi:10.1086/503584

Harrower, S., \& Hoddinott, J. (2005). Consumption smoothing in the Zone Lacutre Mali. Journal of African Economies, 14, 489-519. doi:10.1093/jae/eji007

Kawabata, K., \& Xu, K. C. G. (2002). Preventing impoverishing through protection against catastrophic health expenditure. Bulletin of the World Health Organisation, 80, 612-630.

Lucas, R. E. B., \& Stark, O. (1985). Motivations to remit: Evidence from Botswana. Journal of Political Economy, 93, 901-918. doi:10.1086/261341

Maccini, S., \& Yang, D. (2009). Under the weather: Health, schooling and economic consequencesof early-life rainfall. The American Economic Review, 99, 1006-1026. doi:10.1257/aer.99.3.1006

McIntyre, D., Thiede, M., Dahlgren, G., \& Whitehead, M. (2006). What are the economic consequences for households of illness and paying for healthcare in low- and middle-income country contexts? Social Science \& Medicine, 62, 858-865. doi:10.1016/j.socscimed.2005.07.001

Michel, P., \& Wigniolle, B. (2007). On efficient child making. Economic Theory, 31, 307-326. doi:10.1007/s00199-006-0099-1

Miller, D. L., \& Paulson, A. L. (2007). Risk taking and the quality of informal insurance: Gambling and remittances in Thailand, Working Paper (WP-07-01). Chicago, IL: Federal Bank of Chicago.

Mishra, V., Assche, S. B.-V., Greener, R., Vaessen, M., Hong, R., Ghys, P. D., ... Rutstein, S. (2007). HIV infection does not disproportionately affect the poorer in sub-Saharan Africa. Aids, 21, S17-S28. doi:10.1097/01.aids.0000300532.51860.2a

Nugent, J. (1985). The old age security motive for fertility. Population and Development Review, 11, 75-97. doi:10.2307/ 1973379

Park, C. (2006). Risk pooling between households and risk-coping measures in developing countries: Evidence from Rural Bangladesh. Economic Development and Cultural Change, 54, 423-457. doi:10.1086/497013

Rapoport, H., \& Docquier, F. (2006). The economics of migrants' remittances. In S. Kolm \& J. M. Ythier (Eds.), Handbook of economics of giving, altruism and reciprocity (pp. 1135-1198). London: North Holland.

Ratha, D. (2010). Mobilizing the diaspora for the reconstruction of Haiti-via diaspora bonds [Online]. Retrieved April 22, 2014, from blogs.worldbank.org/peoplemove/mobilizing-the-diaspora-for-reconstruction-of-haiti-via-diaspora-bonds

Schoonbroodt, A., \& Tertilt, M. (2010). Who owns children and does it matter. NBER Working Paper, Vol. 15663. Cambridge: National Bureau of Economic Research.

Stark, O., \& Lucas, R. E. B. (1988). Migration, remittances and the family. Economic Development and Cultural Change, 36 , 465-481. doi:10.1086/451670

Terza, J. V., Basu, A., \& Rathouz, P. J. (2008). Two-stage residual inclusion estimation: Addressing endogeneity in health econometric modeling. Journal of Health Economics, 27, 531-543. doi:10.1016/j.jhealeco.2007.09.009

Wagstaff, A., \& van Doorslaer, E. (2003). Catastrophe and impoverishment in paying for health care: With applications to Vietnam 1993-1998. Health Economics, 12, 921-933. doi:10.1002/(ISSN)1099-1050

Wooldridge, J. M. (2015). Control function methods in applied econometrics. Journal Of Human Resources, $50(2), 420-445$. doi: $10.3368 / \mathrm{jhr} .50 .2 .420$

Xu, K., Evans, D. B., Kawabata, K., Zeramdini, R., Klavus, J., \& Murray, C. J. (2003). Household catastrophic health expenditure: A multicountry analysis. The Lancet, 362, 111-117. doi:10.1016/S0140-6736(03)13861-5 